\title{
Assessing barriers to treatment for all: an analysis of resources for PLHA in Cayo and Stann Creek Districts of Belize
}

\author{
Philisha Mesidor ${ }^{1}$, Eva Burgos ${ }^{2}$, Alexis L Green ${ }^{1}$, Heidi Beidinger ${ }^{1}$ \\ ${ }^{1}$ Department of Biological Sciences, Eck Institute for Global Health, University of Notre Dame, Notre Dame, Indiana, USA, 2 GOJoven Belize (GOBelize), \\ Belmopan City, Belize \\ Keywords: plha, belize, resource inventory, hiv/aids \\ https://doi.org/10.29392/001c.17855
}

\section{Journal of Global Health Reports}

Vol. 4, 2020

\section{Background}

The Joint United Nations Programme on HIV/AIDS (UNAIDS) launched a global campaign, 90:90:90, which aims to ensure that by 2030 : $90 \%$ of the people living with HIV will know their HIV status, 90\% of those diagnosed with HIV will receive sustained ART, and $90 \%$ of those on ART will have durable viral suppression. Belize is striving towards completing this goal and contributing to international efforts for eliminating HIV globally. In order to successfully reach $90 \%$ of the population receiving sustained ART, barriers to care that decrease retention rates must be addressed. To combat barriers to care for Persons Living with HIV/AIDS (PLHA), resources must serve to eliminate the obstacles negatively affecting adherence to treatment.

\section{Methods}

This study aimed to (a) assess treatment and care resources in Cayo and Stann Creek districts and (b) pose questions to key informants to gain deeper understanding of HIV services and patient utilization. The study was conducted from May to July 2016 and focused in Belmopan, San Ignacio, and Dangriga to produce an HIV services inventory for the Cayo and Stann Creek districts.

\section{Results}

Our participants composed of $50 \%$ civil society and 50\% government organizations. $50 \%$ of the locations worked less than 45 hours per week and most commonly served the community by providing training, health fairs, and posters. Resources with the lowest number of facility participation were directly observed therapy (DOT), HIV support group (HSG), and prescriptions. The emerging themes from the key informants were (a) concern with patients' needs, (b) unsustainable resources, and (c) inadequate quality of treatment and care beyond the provider's control. Results convey the gap between the needs of PLHA and what is being offered by the organizations in the community. In addition, key informants note the unsustainable resources that may contribute to the current climate.

\section{Conclusions}

The final product of this study included a report based on the data produced, a patient-friendly brochure in English listing resources available, and an infographic summarizing the findings of this study.

\section{INTRODUCTION}

The goal of eliminating HIV transmission and the AIDS epidemic is within reach. In December 2013, the Joint United Nations Programme on HIV/AIDS (UNAIDS) launched the global campaign, 90:90:90, an ambitious initiative to provide treatment for all PLHA. The campaign aims to ensure by $2030,90 \%$ of the people living with HIV will know their HIV status, 90\% of those diagnosed with HIV will receive sustained antiretroviral treatment (ART), and $90 \%$ of those on ART will have durable viral suppression. ${ }^{1}$
Belize has the highest average annual prevalence rate in Central America. ${ }^{2}$ In 2014, Belize's prevalence rate was estimated at $1.2 \%$ of its population. ${ }^{3}$ Because this percentage is greater than one percent of the population, HIV is labeled a generalized epidemic in Belize. ${ }^{4}$

In 2009, "the adult HIV prevalence rate of Belize was calculated at $2.3 \% " .5$ In 2012 , the HIV prevalence rate was $1.4 \% .^{6}$ The rate decreased by $0.9 \%$ within a span of three years (from 2009 to 2012) with an

additional decrease of $0.2 \%$ from 2012 to 2014. In half a decade, Belize decreased its adult HIV prevalence rate by 
1.1\%. This significant decrease is due to the improvement in surveillance/data collection and increasing providers influence on patient HIV testing.

"The Ministry of Health expanded the Provider Initiated Testing and Counseling

(PITC) approach to the health care system in 2008 and the HIV module of Belize Health Information System (BHIS) was rolled out in 2009, improving efficiency in managing

health data. The year 2008 also marked the first year of the declining trend in reported new HIV infections in Belize." USAID

The expansion of the HIV module of BHIS, amongst other efforts by the Ministry of Health,

resulted in an increase of information about HIV in Belize. In 2014, surveys administered by the

Ministry of Health displayed that approximately one fourth of the population sampled reported

receiving an HIV test and knowing their result. ${ }^{6}$

Belize is determined to partake in the 90:90:90 campaign. To contribute to this global effort, Belize has taken great strides to provide opportunity for their citizens to get tested. Belize continuously constructs methods to increase the adherence rates for ART. Based on UNAIDS ${ }^{1}$ findings, (Figure 1), when compared to its Latin and Caribbean counterparts, Belize has the second lowest percentage of patients retained in ART.

A 2016 report (Figure 2) displays nearly half of the diagnosed were lost to follow up (LTFU) as opposed to successfully transitioning into care and receiving ART. ${ }^{7}$ To combat these statistics, the collective, National HIV/AIDS Program Epidemiology Unit, suggested adding more adherence counselors into the system to reduce existing gaps and increase treatment efforts. Adherence counselors are staff responsible for focusing on PLHA that are susceptible to LTFU and/or having difficulty adhering. These positions were created with the purpose of alleviating the workload of social workers, who-prior to introducing adherence counselors-were solely responsible for all PLHA in Belize's public hospital records.

To resolve this issue, Belize's providers focus on eliminating any existing barriers to care. This can minimize obstacles preventing PLHA from adhering to treatment. Barriers to care, such as psychosocial and tangible barriers, are rooted in the lack of resources. ${ }^{8}$

Psychosocial barriers include stigma and discrimination or an absence of support from loved ones. According to the Statistical Institute of Belize, ${ }^{9} 8.6 \%$ of women and $7.5 \%$ of men ages 15-49 expressed acceptance towards PLHA in Belize, concluding that $91.4 \%$ of women and $92.5 \%$ of men have attitudes that produce stigma towards PLHA.

Tangible barriers include lack of transportation, food scarcity, and inconvenient procedures. The National AIDS Commission of Belize emphasizes creating cost effective strategies and multiple partnerships with health centers, according to the Government of Belize. ${ }^{10}$ In addition, antiretroviral medications (ARVs) are given to patients free of charge in all public hospitals (L. Longsworth, personal communication, May 9, 2016). Nevertheless, there are other costs associated with successful treatment of PLHA. These
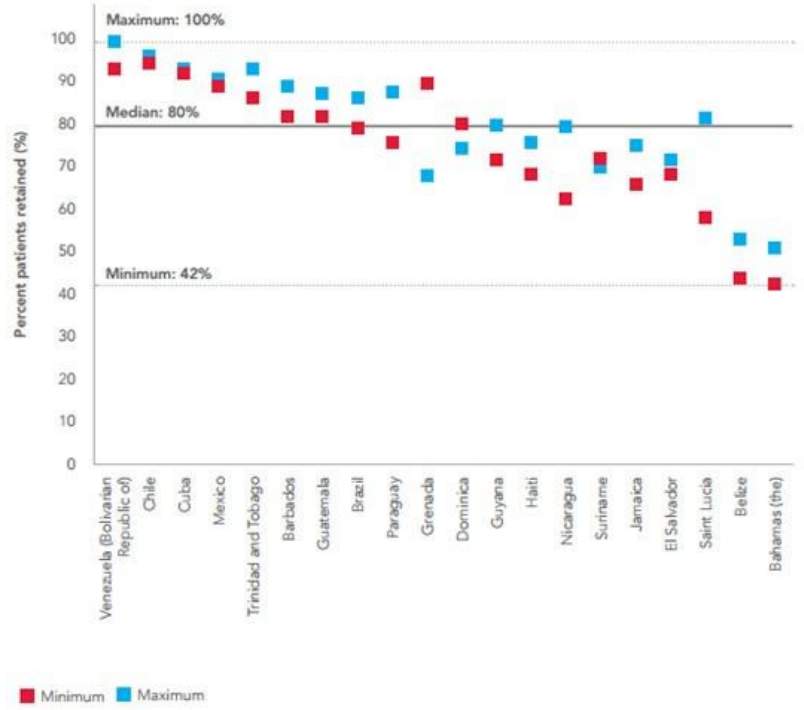

Figure 1.12 and 24-month retention on treatment in Latin America and the Caribbean, 2013.**

Provided by UNAIDS, ${ }^{1}$ this figure shows Belize's retention rates in relation to countries in the same geographical area.

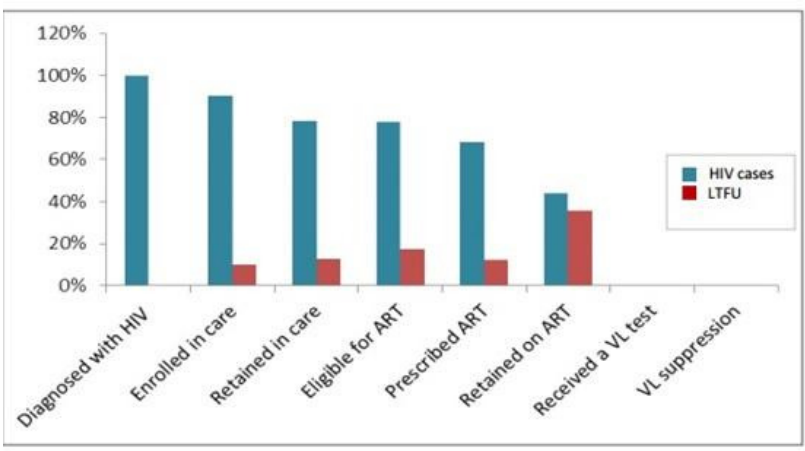

Figure 2. National-level cohort cascade including lostto-follow-up (LTFU) on December 31, 2015.

Figure 2 displays HIV cases that were still participating (blue) versus the case that were lost-to-follow-up (red). ${ }^{7}$

costs include transportation to and from the health clinic and availability of nutritious food.

To mitigate currently present barriers to care, providers anticipate greater funding and flexibility to best assess and fulfill the needs of PLHA. Belize's National AIDS Commission has previously stressed their limited human and financial capacity in providing these resources.
"The financial element will remain a cardinal chal- lenge, particularly in light of competing health priori- ties and when budgetary cuts are being recommended, we are expected to do more with fewer funds so that it is now imperative for the programmes to do more tar- geted intervention and more realistic goal setting if the adequate targets are to be achieved." (p.10) Ministry of Health National HIV/AIDS \& TB Programme ${ }^{11}$

Both Belize's government and civil society (non-govern- 
ment organizations) are aware that their efforts are often undercut by limited resources, observing the effects on patients and public health policy.

Perceived lack of funding can lead to overstressed and underpaid providers that can no longer effectively implement the intended campaign or maintain expected care. The limitations of human and funding capacities and the effects on providers were salient. A metaphor (taken from one of the providers interviewed) provides color and dimension to the health system in Cayo and Stann Creek districts: providing select resources while other necessary resources-such as nutrition vouchers and transportation-for patients are not readily available is "putting icing on a burnt cake". Without empowering providers with tangible resources dependent on their district-specific needs, there is a limit to how effective these interventions can be for PLHA.

\section{METHODS}

\section{STUDY DESIGN}

This study was conducted from May to July 2016 in Cayo and Stann Creek districts of Belize. Our team collected descriptive statistics of each facility and created an inventory of all services provided. We recorded qualitative insights to gain deeper understanding of the health system and patient utilization of HIV services. We recorded descriptive statistics of each facility and interviewed study participants (staff who represented the participating facilities) (Appendix B, C). Descriptive statistics included: official name of the organization, the mission statement and/or population served by the organization, the location (city/town and district) of the organization, the hours of operation (including days open), the organization's contact information (including physical address, email address, phone number, and website), and the type of organization (government or civil society) [civil society is defined as non-government organizations].

We derived our inventory from a Phase III clinical trial originally conducted in Soshanguve Township, Pretoria, South Africa titled FEM-PrEP. The clinical trial focused on pre-exposure prophylaxis for HIV infection among South African women. ${ }^{12}$ The inventory portion of their clinical trial served the purpose of documenting "facility-specific information on services and staffing that can inform public health stakeholders. ${ }^{12}$ Their inventory assessed services related to HIV diagnosis, prevention, family planning, community education and other aspects of HIV campaigns. The categories by FEM-PrEP were used to catalogue the services found in the Belizean facilities observed in our study. The original categories were filtered to accommodate the $\mathrm{Be}$ lizean context and the country's resources. Of the 11 services offered in the original inventory (as shown in Appendix A, the study team included 10 of the services in their checklist. The excluded service was Male Circumcision (MC) as it was not likely that the locations visited would have this service (E. Burgos, personal communication, June 2016).

The interview consisted of collecting participant responses to these four questions: (1) "rank the top three services in this inventory that you believe are most important for patients to access" (2) "what HIV resources do you believe are lacking in their community?", (3) "what ways could patient utilization be improved?", and (4) "what other HIV resources or organizations exist in your community?". These questions were posed to PLHA-focused community stakeholders to supplement the inventory with a narrative that provides deeper understanding of the existence and use of HIV resources. The three sections of this inventory-descriptive statistics, survey responses, and four recorded responses-crafted a dimensional image on how the health system exists from the providers' perspectives.

Participating facilities were obtained via snowball and networking sampling as the researchers aimed to attract as many respondents as possible. An eligible facility was defined as a site where an organization provides services to PLHA. This can be a hospital, clinic, or any office space occupied, whether government or civil society. Private facilities were not eligible for this study, as their services were costlier than their government and civil society counterparts.

A member of our team is the director of an active organization in Belize's civil society, Go Belize. Go Belize provided the team with a list of facilities in three locations: San Ignacio (Cayo district), Belmopan (Cayo district), and Dangriga (Stann Creek district). After visiting a facility and completing the inventory, the team requested references to other organizations that served the HIV community. The replies were used to increase the list until saturation of the known resources was met.

Navigators, made available by Go Belize, were used to discover participating facilities. The navigators (three in total, one for each city) had insight on the different facilities visited, a firm understanding of the health system specific to the region, and made introductions to participants who were otherwise apprehensive.

The interview questions were coded and analyzed to reveal emerging themes and clarify the field of HIV resources in Cayo and Stann Creek districts. The qualitative coding and analysis used were written by Creswell. ${ }^{13}$ The team followed the procedures for data collection, recording, and interpretation in addition to procedures to increase validity (p.179-206). Member checking and responders' validity were used to maximize the accuracy of the interview responses. At the completion of the study, study participants were invited to discuss the findings.

\section{SAMPLE SIZE AND STATISTICAL ANALYSIS}

Sample size was based on the health system in Belize, which included both government and civil society. In the community, the roles of stakeholders and participating facility representatives overlap. Many representatives who are employed by participating facilities also serve as PLHA-focused stakeholders and/or are active members of both government and civil society. When inquiring about other stakeholders, we were often referred to previously interviewed representatives. Because of this, the representatives of the facilities served as stakeholders for the purpose of this study.

All of the statistical analysis was descriptive; this study included a qualitative coding and analysis of the study participants' responses to compliment these statistics. We vis- 
Table 1. Weekly working hours per facility

\begin{tabular}{|l|r|r|}
\hline Statistics & Data points & Without outliers \\
\hline Mean & 71.04 & 38.72 \\
\hline Min & 12 & 12 \\
\hline 25 Percentile & 28.25 & 24.5 \\
\hline Median & 44.75 & 44.5 \\
\hline 75 Percentile & 122.5 & 45 \\
\hline Max & 168 & 77 \\
\hline
\end{tabular}

ited 19 facilities. Seven of the 19 facilities were excluded. Four facilities were excluded because they were sites for HIV committees and did not provide direct services to PLHA. Three facilities were excluded because they did not provide services specifically to PLHA.

In total, there were 12 participating facilities, complete with 12 study participants. Four different facilities served each of the three cities (San Ignacio, Belmopan, Dangriga). Out of the four in each location, there were two government and two civil society organizations.

Data analysis included descriptive findings, such as what populations are most served in the three locations and what services are most commonly provided. The qualitative questions were coded and analyzed to reveal emerging themes that increased the depth of this study and the clarity of HIV resources in Cayo and Stann Creek districts. The study team used qualitative coding and analysis written by Creswell. ${ }^{13}$ This included data collection, data recording, data analysis and interpretation, and validity procedures (p. 179-206). To increase validity, we presented the conclusions of the study to the study participants. Our intent is to ensure the emerging themes produced from the interviews were accurate and that the participants' words were recorded as intended. We shared the study design with our in-country partner, Go Belize, including the methods used and provided the inventory sheet template to Go Belize. This study can be conducted by Go Belize in the future in order to update their organizational matrix, as the health system continues to improve.

\section{ROLE OF FUNDING SOURCE}

The study sponsors did not have any role in study design, data analysis and interpretation, the writing and editing of this report, or the decision to submit this paper for publication. The corresponding author had full access to all the data in the study and had final responsibility for the decision to submit for publication.

\section{RESULTS}

We included 12 participating facilities in the survey, resulting in 50\% civil society and 50\% government organizations. The findings were obtained with the aid of Go Belize navigators to increase the probability that we surveyed all operating locations (Figure 3). In the participating locations, 50\% of the locations worked less than 45 hours per week (Table

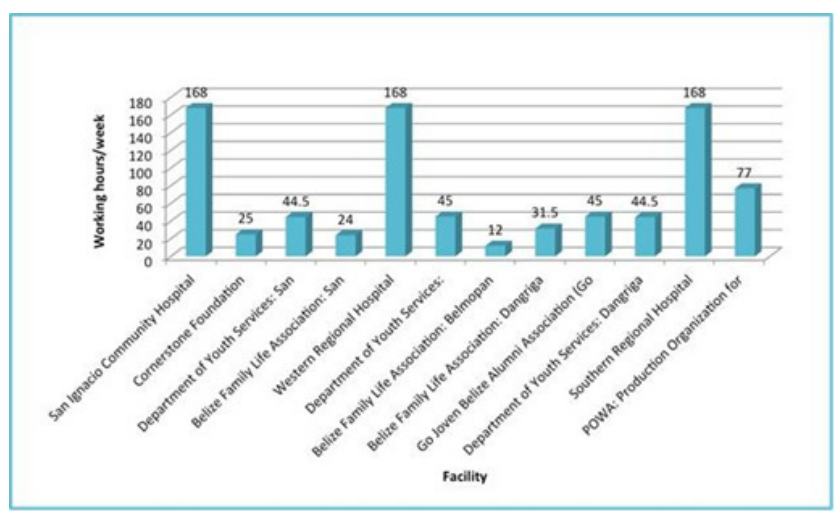

Figure 3. Weekly working hours per facility.

This figure shows working hours ranging from 12 to 168 hours a week.

1). Of the services provided by each facility, training, health fairs, and posters were the most common. Directly observed therapy (DOT), HIV support group (HSG), and prescriptions have the lowest number of facility participation (Table 2).

When questioned "Of all the services discussed, rank the top three you believe are most important for patients to access.", the most frequent responses were prescription, ARVs, and HIV support groups (Figure 4). The responses that were ranked highest were ARVs, prescriptions, and voluntary counseling and testing. HIV support groups were the third most frequently mentioned, but only three of the participating facilities provide this service.

When questioned "What HIV resources do you think are lacking in your community?", the three topics of discussion were needs, resources, and care and treatment of the patient. This stemmed from widespread concern for a broad range of patient needs (including non-medical needs). Resources are limited or lacking for both providers and patients and include physical and economical aspects of care.

When questioned "In what ways could patient utilization of HIV resources be improved?”, responses centered on patient services, patient experience, and capacity strengthening. Strategic placement of social services and mitigating potential discrimination by fellow peers and/or health officials may increase patient utilization of services. Additionally, there is a need for strengthening networks and increasing the collaboration between civil society and government facilities.

Responses were transcribed verbatim, organized under 
Table 2. Facilities providing each service

\begin{tabular}{|c|c|c|c|c|c|}
\hline \multicolumn{6}{|c|}{ Facilities Providing Each Service } \\
\hline Services & $\begin{array}{l}\text { Number of } \\
\text { facilities }\end{array}$ & Percentage & Services & $\begin{array}{l}\text { Number of } \\
\text { facilities }\end{array}$ & Percentage \\
\hline $\begin{array}{l}\text { Voluntary counseling \& testing } \\
\text { (VCT) }\end{array}$ & 7 & $58.33 \%$ & Prescription & 2 & $16.67 \%$ \\
\hline $\begin{array}{l}\text { Provider-initiated counseling \& } \\
\text { testing (PITC) }\end{array}$ & 5 & $41.67 \%$ & Training & 12 & $100 \%$ \\
\hline Mobile HIV testing (MBT) & 7 & $58.33 \%$ & $\begin{array}{l}\text { Community } \\
\text { Meetings }\end{array}$ & 8 & $66.67 \%$ \\
\hline STI testing \& treatment (STI) & 6 & $50.00 \%$ & Workshops & 11 & $91.67 \%$ \\
\hline HIV care $\&$ treatment (ARVs) & 4 & $33.33 \%$ & $\begin{array}{l}\text { Special } \\
\text { Events }\end{array}$ & 9 & $75.00 \%$ \\
\hline Family Planning (FP) & 7 & $58.33 \%$ & Health Fairs & 12 & $100 \%$ \\
\hline $\begin{array}{l}\text { Prevention of mother to child } \\
\text { transmission (PMTCT) }\end{array}$ & 4 & $33.33 \%$ & Theatre & 3 & $25.00 \%$ \\
\hline Home based HIV care (HBC) & 5 & $41.67 \%$ & Posters & 12 & $100 \%$ \\
\hline $\begin{array}{l}\text { Directly-observed therapy (DOT) for } \\
\text { ART }\end{array}$ & 2 & $16.67 \%$ & Videos & 8 & $66.67 \%$ \\
\hline HIV support groups (HSG) & 3 & $25.00 \%$ & Brochures & 11 & $91.67 \%$ \\
\hline
\end{tabular}

categories, and coded into emerging themes (as the method Creswell ${ }^{13}$ stated). The emerging themes found in this study were (a) concern with patients' needs, (b) unsustainable resources, and (c) inadequate quality of treatment and care beyond the provider's control.

The responses recorded focused on a great concern for patients' needs, both medical and non-medical. Study participants clarified that-despite the effort placed on an international, intra-national, and inter-organizational level-needs of PLHA are not being satiated by what government and civil society can provide. PLHA need unwavering support from the moment they learn of their status. PLHA are not comfortable entering the medical system, according to the respondents. In response, the Belizean Ministry of Health has implemented integrative services, which reformed the routines of PLHA from visiting HIV/AIDS specialized physicians to visiting physicians that other patients in care visit. The purpose of integrative services is to reduce the feeling of isolation. However, multiple respondents explained that it increases the uneasiness of PLHA because they perceive it as a larger risk to being disclosed. For example, receiving their medication at the general pharmacy in an unmarked package can command more attention from other patients.

According to respondents, the economic and physical resources are unsustainable for both the patient level and the provider level. Patients may not have the economic freedom to pay for transportation to and from the hospital. Some hospitals are far from bus routes that patients utilize and patients need to take a taxi each visit. This causes an excess burden to the patient. Other patients may not have funds to obtain nutritious food, which can affect the success of their treatment. One respondent stated that providing free ARVs without also finding ways to reduce their other costs, such as food and housing is "like putting icing on a burnt cake". Providers also struggle to support their patients by finding

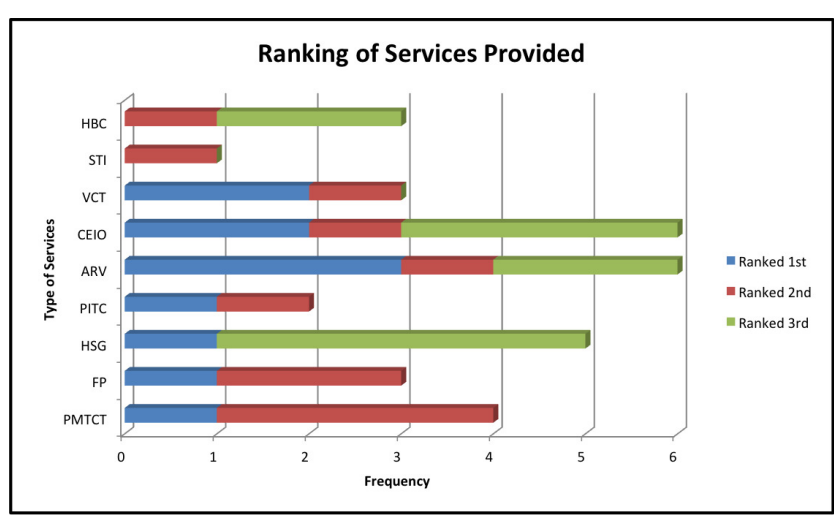

Figure 4. Ranking of services provided.

Participants ranked their top three most important services discussed.

funds for food vouchers or baskets, often using part of their salary to help their clients. One participant recalled having to use their personal funds and materials to publish posters and provide materials for public campaigns, despite expecting their organization to provide these resources.

Furthermore, there are limited resources for providers, including manpower. The amount of services provided by the facilities is significantly greater than the number of staff. The staff is often overworked with minimal resources and flexibility. These needs serve as a hindrance. Providers' ability to give quality services and provide opportunities for their patients influences the patients, particularly their perception of ARVs and their ability to adhere.

Study participants recall that many of their HIV support group meetings include discussing the quality of treatment and care provided by health care providers. Patients may feel unwelcomed by their providers. PLHA may feel mistreated and discriminated against by providers when seek- 
ing care, leading to avoidance. Some patients decide to wait until they can afford to travel outside their area to seek better care. This can affect their adherence to treatment.

Inefficient testing can hinder treatment and care for the study participants. Belize's health system is centralized; all laboratory testing must be conducted in Belize City. For cities that are a great distance from Belize City, the providers are forced to obtain the blood work early, as it needs to reach Belize City by a certain time. If the package does not reach Belize City by the deadline, it isn't accepted. This means the provider must track down the patient, create another appointment and repeat the process. If there is any mismanagement of the vehicle transporting the blood work and/or the package which the blood work is included in, it will also not be accepted. Because of these regulations (though in place with positive intentions), providers are often required to retest many of their patients. This is an arduous task and a burden on both the provider and patient.

\section{DISCUSSION}

The objectives were to (a) assess treatment and care resources in Cayo and Stann Creek districts and (b) pose questions to key informants to gain deeper understanding of HIV services and patient utilization. The results discovered included an insight into how providers perceive the health system and how consistently being underfunded and overworked negatively affects PLHA they serve. This is a reminder that though national efforts are implemented and resources are funneled to providers, they may be inadequate and inefficient for the existing needs. The Belizean Ministry of Health continues to work with both government facilities and civil society to improve the conditions that may lead to barriers to care. The open communication between the different organizations leads to capacity strengthening, one of the concerns stated above.

In perspective, the existing lack of resources can affect Belize's contribution to the UNAIDS 90:90:90 goal. ${ }^{1}$ For 90\% of Belize's population to know their HIV status, community education, outreach services, and testing must be done. With the restriction of funds and flexibility, it is more difficult to attain this goal. For $90 \%$ of those diagnosed to receive sustained ART, they must have transportation to and from the health facility, have proper nutrition, and support. Providers' responses display that the great need disables willing PLHA from receiving the treatment they need. The final objective of the 90:90:90 goal focuses on viral suppression, which can only occur after long term adherence to treatment. Sustainable resources must be instilled into the healthy system, on all levels, so there is a greater likelihood that a patient can adhere with minimal distress.

Study participants believed patient utilization increases when providers introduce positive experiences to patients. Patients are more likely to access services when providers are persuasive. If providers are fatigued, they will not appear as genuine and invested. Provider fatigue may also translate to less patience and tolerance, meaning patients may not receive their prescription education in a welcoming manner.

Prevention of fatigued providers may positively affect patient utilization. Seeking ways to replenish providers, both through funding and non-funding methods, is important for mitigating provider fatigue. Study providers believe that it is their primary responsibility to improve treatment and care for PLHA; it is a top priority. Training sessions, organizational matrix meetings, community capacity strengthening, and inter-organizational referral forms can form a foundation for future collaboration/communication and lessen weariness among staff.

Our team utilized descriptive statistics for our study, which introduced limitations on the data collected. Our data is most meaningful in the context in which we originally collected it. While we are unable to use our data to generalize to other populations, the findings of this research can serve as a foundation for any future research related to HIV/ AIDS efforts in Belize. The results gave participants access to information about their district that they did not have previously.

To increase validity of findings, we presented our data to members of the participating facilities. Our recommendations included increasing the availability of HIV support groups for PLHA. This can encourage patient utilization and provide a safe space for members to discuss their obstacles. We recommended a periodical update of information followed by sharing the information with the other institutions in the health system to increase accuracy and access for patients throughout the country. After discussing these recommendations with respondents, we included providing more funds and availability for providers, which will lead to a positive influence on care.

Limitations in our study include our method of obtaining participants. We used the snowball method, as there previously was not a comprehensive list of institutions providing care to PLHA. There may be institutions that are currently serving PLHA that we did not survey.

The participating facilities self-reported their data and the qualitative portion of the study may introduce bias. However, our study accounts for these limitations by incorporating provider perspectives into the recommendations (as seen above).

\section{CONCLUSIONS}

We provided patient-friendly brochures cataloging the institutions (Appendix D, E) to the participants. Additionally, we provided an infographic-a visual representation-of the findings identified in this study (Appendix F, G). This will be used to provide information to PLHA to increase their ease of access.

After presenting the findings of our study, the Belizean Ministry of Health, government institutions, and civil society used the results to continuously improve the barriers to care. They are working on capacity strengthening and exploring efficient methods on providing sufficient support to PLHA. This sets the country on an optimal path to reach the standards set by the UN's 90:90:90 campaign.

\section{ACKNOWLEDGEMENTS}

The authors are incredibly grateful to the faculty members, 
staff, and management of the Eck Institute for Global Health, University of Notre Dame, United States of America for their support and collaboration in making this study possible.

\section{FUNDING}

None.

\section{AUTHORSHIP CONTRIBUTIONS}

PM, EB, and HB designed the study. PM and ALG compiled the data and did the analyses. EB and HB contributed to the interpretation of the results. PM wrote the first draft of the manuscript. All authors read, improved, and approved the final manuscript.

\section{COMPETING INTERESTS}

The authors completed the Unified Competing Interest format www.icmje.org/coi_disclosure.pdf (available upon request from the corresponding author), and declare no conflicts of interest.

\section{CORRESPONDENCE TO:}

Philisha Mesidor

MS Global Health

Department of Biology

Eck Institute for Global Health

University of Notre Dame, Indiana, USA.

philishamesidor@gmail.com

Submitted: September 12, 2020 GMT, Accepted: October 10, 2020 GMT

This is an open-access article distributed under the terms of the Creative Commons Attribution 4.0 International License (CCBY-4.0). View this license's legal deed at http://creativecommons.org/licenses/by/4.0 and legal code at http://creativecommons.org/licenses/by/4.0/legalcode for more information. 


\section{REFERENCES}

1. Joint United Nations Programme on HIV/AIDS (UNAIDS). 90-90-90: An ambitious treatment target to help end the AIDS epidemic. http://www.unaids.or $\mathrm{g} /$ sites/default/files/media asset/90-90-90 en 0.pdf. Accessed April 5, 2016.

2. Vu L, Nieto-Andrade B, DiVincenzo A, et al. Effectiveness of behavior change communications for reducing transmission risks among People Living with HIV in 6 countries in Central America. AIDS Behav. 2014;19(7):1203-1213. doi:10.1007/s10461-014-091 $\underline{0-0}$

3. The World Bank. Prevalence of HIV, total (\% of population ages 15-49. March 2016:15-49. http://dat a.worldbank.org/indicator/SH.DYN.AIDS.ZS?location s=BZ. Accessed March 29, 2016.

4. UNICEF. How widespread is the AIDS epidemic? March 2016. http://www.unicef.org/aids/index_epide mic.html. Accessed March 29, 2016.

5. USAID. Getting to zero: Belize HIV strategic plan 2012-2016. http://hivhealthclearinghouse.unesco.or $\mathrm{g} /$ sites/default/files/resources/Belize_HIV_Strateg.

6. Global AIDS Country Progress Report. Country of Belize. Submitted by National AIDS Commission on March 31, 2014.; 2014.

7. National HIV/AIDS Program Epidemiology Unit. Annual HIV Statistical Report.; 2016. http://www.una ids.org/sites/default/files/country/documents/BLZ na rrative_report_2016.pdf. Accessed April 27, 2016.
8. Bogart LM, Chetty S, Giddy J, et al. Barriers to care among People Living with HIV in South Africa: Contrasts between patient and healthcare provider perspectives. http://www.iapac.org/AdherenceConfer ence/presentations/ADH7 79372.pdf. Accessed April 14, 2016.

9. Statistical Institute of Belize. Knowledge, attitude and practices in sexual behaviour and HIV in Belize. Country Report. 2014.

10. Government of Belize Office of Governance. HIV/ AIDS policy of the public service of Belize. http://ww w.ilo.org/wcmsp5/groups/public/---ed_protect/---pro trav/---ilo_aids/documents/legaldocument/wcms_127 747.pdf. Accessed April 5, 2016.

11. Ministry of Health National HIV/AIDS \& TB Programme. National TB HIV/AIDS \& other STI programme. http://health.gov.bz/www/attachments/a rticle/849/TB\%20\%26\%20HIV\%20Programmatic\%20R eport\%202014.pdf. Accessed April 14, 2016.

12. FHI 360. HIV services inventory final report. htt p://www.fhi360.org/sites/default/files/media/docume nts/Fem-Prep\%20HIV\%20service. Accessed April 14, 2016.

13. Creswell JW. Research Design: Qualitative, Quantitative, and Mixed Method Approaches. Thousand Oaks, Calif: Sage Publications 


\section{SUPPLEMENTARY MATERIALS}

\section{Online Supplementary Document}

Download: https://www.joghr.org/article/17855-assessing-barriers-to-treatment-for-all-an-analysis-of-resources-forplha-in-cayo-and-stann-creek-districts-of-belize/attachment/46435.docx 